ORIGINAL ARTICLE

\title{
Aberrant cellular retinol binding protein 1 (CRBP1) gene expression and promoter methylation in prostate cancer
}

\author{
C Jerónimo, R Henrique, J Oliveira, F Lobo, I Pais, M R Teixeira, C Lopes
}

J Clin Pathol 2004;57:872-876. doi: 10.1136/icp.2003.014555

See end of article for authors' affiliations

Correspondence to:

Dr C Jerónimo,

Department of Genetics, Portuguese Oncology Institute Rua Dr António

Bernardino de Almeida, 4200-072 Porto, Portugal; cjeronimo@hotmail.com

Accepted for publication 3 March 2004
Aims: Retinoids are involved in cell growth, differentiation, and carcinogenesis. Their effects depend on cytosolic transport and binding to nuclear receptors. CRBP1 encodes a protein involved in this process. Because altered CRBP1 expression and promoter hypermethylation occur in several tumours, these changes were investigated in prostate tumorigenesis.

Methods: The CRBP1 promoter was assessed by methylation specific polymerase chain reaction on tissue samples from 36 radical prostatectomy specimens (paired normal tissue, adenocarcinoma, and high grade prostatic intraepithelial neoplasia (HGPIN)), 32 benign prostatic hyperplasias (BPHs), and 13 normal prostate tissue samples from cystoprostatectomies. Methylation of DNA extracted from microdissected tissue was examined blindly. CRBP1 expression was assessed by immunohistochemistry on formalin fixed, paraffin wax embedded tissue.

Results: Loss of CRBP1 expression was seen in 15 of 36 adenocarcinomas and 18 of 36 HGPINs. Fifteen adenocarcinomas and nine HGPINs showed overexpression, whereas the remainder showed normal expression. BPH displayed normal expression. No significant associations were found between CRBP1 expression and Gleason score or stage. CRBP1 promoter hypermethylation was found in 17 of 36 adenocarcinomas, three of 35 HGPINs, one of 36 normal prostate tissues from the same patients, none of $32 \mathrm{BPHs}$, and none of 13 normal prostate tissues from cystoprostatectomies. Loss of expression and hypermethylation of CRBP1 were not significantly associated.

Conclusions: Altered CRBP1 expression and hypermethylation are common in prostate carcinoma, although CRBP1 hypermethylation is not an early event in tumorigenesis. Moreover, both adenocarcinoma and HGPIN show frequent CRBPI overexpression. The molecular mechanisms underlying altered CRBP1 expression in prostate cancer deserve further study.
$\mathrm{R}$ etinoids are structural and functional analogues of vitamin A known to mediate cellular signals promoting differentiation and cell arrest at Gl phase. ${ }^{1}$ They are inhibitors of tumorigenesis, can reverse preneoplastic lesions, and may prevent second primary tumours of the upper aerodigestive tract. ${ }^{2-5}$ Furthermore, the use of 9-cis-retinoic acid inhibits mammary tumours induced by $\mathrm{N}$-nitroso- $\mathrm{N}$ methylurea, although other tumours show resistance to the action of retinoids by mechanisms still largely unknown. ${ }^{6}$

"Retinoids have been shown to inhibit prostate cancer cell growth in vitro and to suppress prostate carcinogenesis through a signalling pathway that involves both nuclear hormone receptors and cytoplasmic carriers"

The cellular retinol binding proteins (CRBPs) are an important component of retinoid activity, and these proteins are thought to participate in the metabolism of retinoids within the cell by presenting the ligand to specific metabolic enzymes. ${ }^{78}$ CRBPs are monomeric proteins of approximately $15.5 \mathrm{kDa}$, belonging to a family of small cytoplasmic proteins that specifically interact with hydrophobic ligands, the intracellular lipid binding proteins. In humans, three of these retinol carriers have been described: CRBPI, which displays wide tissue expression, and CRBP2, and CRBP3, which are expressed in a tissue specific manner. ${ }^{8}$ Although, their precise function is complex and not yet fully understood, CRBPs are thought to facilitate the formation of retinyl esters for storage or conversion of retinol to retinoic acid. ${ }^{9}$ Indeed, recent studies of knockout mice indicate a crucial role for CRBPl in maintaining normal hepatic retinol storage. ${ }^{10}$ These studies demonstrated that CRBPl is needed to facilitate the conversion of retinol to retinyl ester, thus slowing retinol turnover in the liver. ${ }^{10}$

The possible role of altered CRBPl expression in human carcinogenesis is still largely unknown. However, CRBPl downregulation has been associated with the malignant phenotype, most notably in breast and ovarian cancer.9 ${ }^{11} 12$ Loss of CRBPI expression was reported in $22 \%$ and $27 \%$ of invasive and in situ breast carcinomas, respectively, ${ }^{11}$ whereas in ovarian cancer this proportion reaches $35 \% .{ }^{12}$ Recently, Esteller et al suggested that aberrant methylation at the promoter region may be one of the mechanisms underlying CRBPl silencing in tumour cell lines and in primary tumours. ${ }^{13}$

Retinoids have been shown to inhibit prostate cancer cell growth in vitro and to suppress prostate carcinogenesis through a signalling pathway that involves both nuclear hormone receptors and cytoplasmic carriers. ${ }^{14}$ Because the role of CRBPl in this process has not been previously investigated, we aimed to characterise CRBPl expression in a series of prostate carcinoma (PCa) lesions and paired high grade prostatic intraepithelial (HGPIN) lesions from patients undergoing radical prostatectomy. Furthermore, CRBPI promoter methylation status was analysed to investigate a possible association with aberrant gene expression. To the

Abbreviations: $\mathrm{BPH}$, benign prostatic hyperplasia; $\mathrm{CRBP}$, cellular retinol binding protein; HGPIN, high grade prostatic intraepithelial neoplasia; $\mathrm{LOH}$, loss of heterozygosity; MSP, methylation specific polymerase chain reaction; PBS, phosphate buffered saline; PCa, prostate carcinoma; PCR, polymerase chain reaction; PIN, prostatic intraepithelial neoplasia; PSA, prostate specific antigen 
best of our knowledge no such study has been performed to date.

\section{MATERIAL AND METHODS Patients}

Thirty six patients primarily treated with radical prostatectomy at the Portuguese Oncology Institute - Porto, Portugal for clinically localised prostate adenocarcinoma and simultaneously harbouring foci of HGPIN were selected for our study. Each tumour was graded and staged according to the Gleason grading system ${ }^{15}$ and the TNM staging system, ${ }^{16}$ respectively. For control purposes, morphologically normal tissue was procured from each of the 36 radical prostatectomy specimens and also from 13 prostates collected from cystoprostatectomy specimens from patients with bladder cancer, which did not harbour prostate cancer. Tissue samples were also obtained from 32 randomly selected patients with benign prostatic hyperplasia (BPH), who had undergone transurethral resection of the prostate. A representative slide of PCa, HGPIN, BPH, and normal tissue was selected for immunohistochemical analysis.

\section{Immunohistochemical analysis}

Sections $(4 \mu \mathrm{m})$ were cut and placed in aminopropyltriethoxysilane (catalogue number A-3648; Sigma, Poole, Dorset, UK) coated slides. Immunostaining was performed using a streptavidin-biotin complex peroxidase method (Dako, Glostrup, Denmark), as described previously by Neuville et al. ${ }^{17}$ Briefly, after dewaxing the sections, endogenous peroxidase activity was inhibited with freshly prepared $0.5 \%$ hydrogen peroxide in distilled water for 20 minutes. Next, the sections were processed in a $600 \mathrm{~W}$ microwave oven, at maximum power, three times for five minutes in citrate buffer ( $\mathrm{pH}$ 6.0). Incubation with the polyclonal goat antiCRBPl antibody (clone N-17; Santa Cruz Biotechnology Inc, Santa Cruz, California, USA) was performed overnight at $4{ }^{\circ} \mathrm{C}$, at a dilution of $1 / 50$ in $1 \%$ bovine serum albumin in phosphate buffered saline (PBS). According to the manufacturer's information, this antibody is specific for CRBPI of human origin. All of the incubations were performed in a humidified chamber. Sections were developed with a peroxidase substrate solution $(0.05 \%$ 3,3-diaminobenzidine tetrahydrochloride, $0.01 \% \mathrm{H}_{2} \mathrm{O}_{2}$ in $\mathrm{PBS}$ ), counterstained with haematoxylin, dehydrated, and mounted. Appropriate positive controls were used for each antibody and negative controls consisted of the replacement of the primary antibody with $1 \%$ bovine serum albumin in PBS.

The assessment of CRBPl expression was performed by light microscopy at $\times 400$ magnification by two independent observers blinded to clinical and methylation analysis data. The immunostaining was evaluated in morphologically normal areas, HGPIN lesions, adenocarcinoma, and BPH, and was graded and scored by visual assessment of the intensity of the brown reaction product in the areas of interest ( 0 , no immunostaining; $1+$, immunostaining similar to normal glands; and 2+, immunostaining stronger than in normal glands).

\section{Methylation analysis}

Snap frozen tissue specimens, corresponding to those analysed by immunohistochemistry, were used for methylation specific polymerase chain reaction (MSP) analysis. Sections ( $5 \mu \mathrm{m}$ thick) were cut and stained to identify the areas of HGPIN, adenocarcinoma, normal tissue, and BPH. Then, the tissue block was trimmed to maximise the yield of target cells ( $>70 \%$ of target cells). Subsequently, an average of $50 \times 12 \mu \mathrm{m}$ thick sections were cut and every fifth section was stained to ensure a uniform proportion of target cells and to exclude contamination by neoplastic cells in normal and $\mathrm{BPH}$ tissue samples.

Genomic DNA was extracted according to the method described by Ahrendt et al. In short, DNA was digested overnight at $48^{\circ} \mathrm{C}$ with proteinase $\mathrm{K}(0.5 \mathrm{mg} / \mathrm{ml})$ in $1 \%$ sodium dodecyl sulfate, Tris ( $1 \mathrm{M}, \mathrm{pH} 8.8)$, EDTA $(0.5 \mathrm{M}$, $\mathrm{pH} 8.0)$, and $\mathrm{NaCl}(5 \mathrm{M})$, followed by phenol/chloroform extraction $(2 \mathrm{vol} / 1 \mathrm{vol})$ and ethanol precipitation. ${ }^{18}$

\section{Bisulfite treatment}

Bisulfite treatment of DNA converts unmethylated cytosines to uracil, but the methylated ones remain as cytosines. Sodium bisulfite conversion of $2 \mu \mathrm{g}$ of genomic DNA was performed by the modification of a previously described method. ${ }^{19}$ In brief, DNA was denatured in $0.2 \mathrm{M} \mathrm{NaOH}$ for 20 minutes at $50^{\circ} \mathrm{C}$. A volume of $500 \mu \mathrm{l}$ of freshly made bisulfite solution $(2.5 \mathrm{M}$ sodium metabisulfite and $125 \mathrm{mM}$ hydroquinone, $\mathrm{pH}$ 5.0) was added to each sample and incubation was continued at $50^{\circ} \mathrm{C}$ for three hours in the dark. Modified DNA was purified using the Wizard DNA purification resin according to the manufacturer (Promega Corp, Madison, Wisconsin, USA) and eluted in $45 \mu \mathrm{l}$ of water at $80^{\circ} \mathrm{C}$. After treatment with $\mathrm{NaOH}$ (final concentration $0.3 \mathrm{M}$ ) for 10 minutes at $37^{\circ} \mathrm{C}$, isolation was continued with $75 \mu \mathrm{l} 7.5 \mathrm{M}$ ammonium acetate, followed by an incubation step of five minutes at room temperature. Finally, the modified DNA was precipitated by adding 2.5 volumes of $100 \%$ ethanol and $2 \mu \mathrm{l}$ glycogen $(5 \mathrm{mg} / \mathrm{ml})$. Each resulting DNA pellet was washed with $70 \%$ ethanol, dried, resuspended in $30 \mu \mathrm{l}$ of $5 \mathrm{mM}$ Tris/ $\mathrm{HCl}(\mathrm{pH} 8.0)$, and stored at $-20^{\circ} \mathrm{C}$.

\section{CRBP 1 promoter methylation status}

DNA methylation patterns in the CpG island of the CRBPl gene promoter were determined by MSP. ${ }^{20}$ For polymerase chain reaction (PCR) amplification, $2 \mu \mathrm{l}$ of bisulfite modified DNA was added in a final volume of $25 \mu \mathrm{l}$ PCR mix containing $1 \times$ PCR buffer $(16.6 \mathrm{mM}$ ammonium sulfate, $67 \mathrm{mM}$ Tris, $\mathrm{pH} 8.8,6.7 \mathrm{mM} \mathrm{MgCl}_{2}$, and $10 \mathrm{mM}$ 2-mercaptoethanol), dNTPs (each at $1.25 \mathrm{mM}), 1 \mathrm{U}$ Hot Start Taq DNA polymerase (Qiagen, Hilden, Germany), and primers (300 ng each reaction). The CRBPl primer sequences used in our study were those described previously by Esteller et al. ${ }^{13}$ MSP was carried out using the following conditions: one cycle at $95^{\circ} \mathrm{C}$ for one minute, followed by 35 cycles of one minute at $95^{\circ} \mathrm{C}$, one minute at $62^{\circ} \mathrm{C}$, and one minute at $72^{\circ} \mathrm{C}$, with a final extension for five minutes at $70^{\circ} \mathrm{C}$. Leucocyte DNA collected from healthy individuals was used as a negative control. The same leucocyte DNA was methylated in vitro with SssI bacterial methyltransferase (New England Biolabs Inc, Hitchin, Hertfordshire, UK) and used as a positive control for methylated alleles. The PCR products were directly loaded on to a non-denaturing $6 \%$ polyacrylamide gel, stained with ethidium bromide, and visualised under ultraviolet illumination.

\section{Statistical analysis}

The Mann-Whitney U test was used to compare the serum prostate specific antigen (PSA) concentrations between patients with prostate cancer and $\mathrm{BPH}$. All remaining comparisons for significance were performed by means of the $\chi^{2}$ test or Fisher's exact test, as appropriate. All $\mathrm{p}$ values represent two tailed tests and were considered significant at 0.05 .

\section{RESULTS}

\section{Clinicopathological data}

We studied 36 patients with clinically localised prostate adenocarcinoma with a median age of 64 years (range, 4074). As control groups, 32 patients with BPH (median age, 

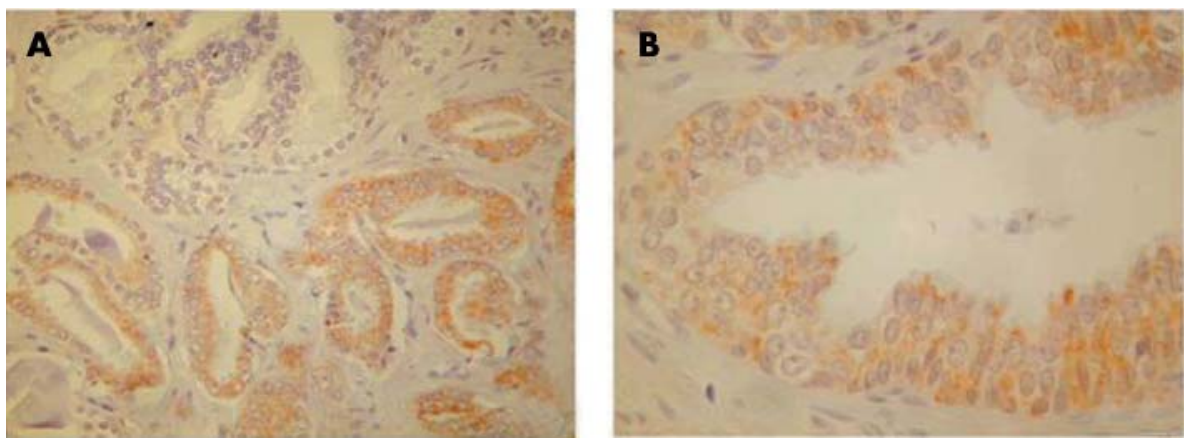

Figure 1 Immunohistochemical expression of CRBP1 in prostate: (A) overexpression in adenocarcinoma, contrasting with low expression in a normal gland (upper leff); (B) overexpression in a high grade prostatic intraepithelial neoplasia lesion (streptavidin-biotin complex peroxidase method with haematoxylin counterstain)

68 years; range, 54-80) and 13 patients submitted to cystoprostatectomy for bladder cancer (median age, 61 years; range, 49-80) were included. The median values of preoperative serum PSA were $8.0 \mathrm{ng} / \mathrm{ml}$ (range, 3.35-16.9) and $5.23 \mathrm{ng} / \mathrm{ml}$ (range, 0.4-32.5) for patients with cancer and $\mathrm{BPH}$, respectively, and this difference reached significance $(\mathrm{p}=0.01)$. The median Gleason score of the prostate adenocarcinomas was 6 (range, 4-9). Of the radical prostatectomy specimens, three cases were staged as pT2a, 17 as pT2b, 13 as pT3a, and three as pT3b.

\section{Immunohistochemical analysis}

In all BPHs, the cytoplasmic expression of CRBPl was similar to that seen in the normal glands (fig lA).

Fifteen PCa lesions showed loss of CRBPl expression, whereas of the remaining 21 cases with CRPBl expression, six showed a similar degree of immunoreactivity to that of normal glands, and 15 showed increased CRBPI immunoexpression (fig 1A). No significant association was found between CRBPl expression and the Gleason score or the pTNM stage (table 1).

With regard to HGPIN, 18 cases showed loss of CRBPI immunoreactivity, nine cases displayed a similar degree of immunoreactivity to that of normal glands, and nine cases showed increased CRBPl immunoreactivity (fig 1B).

No differences were noted between HGPIN and PCa regarding CRBPl expression $(\mathrm{p}=0.34)$. Discrepant patterns of CRBPl expression between paired PCa and HGPIN lesions were seen in eight cases. Specifically, in four cases the PCa displayed CRBPl overexpression, whereas HGPIN showed loss of expression, in three cases the PCa showed increased expression and HGPIN showed normal expression, and in

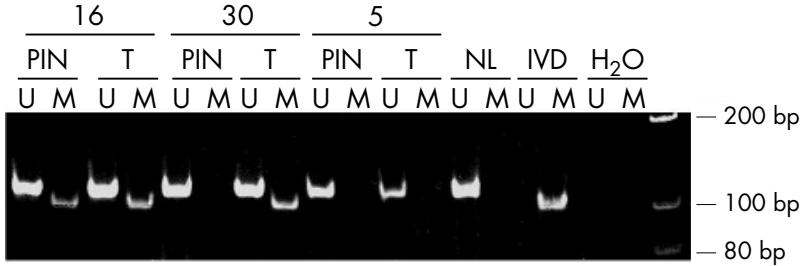

Figure 2 Illustrative example of methylation specific polymerase chain reaction for the CRBP1 promoter region in high grade prostatic intraepithelial neoplasia (PIN) and adenocarcinoma (T). Lanes $U$ and $M$ correspond to unmethylated (109 bp) and methylated (99 bp) reactions, respectively. In patient 16 , both lesions are methylated, whereas in patient 5 both are unmethylated. In patient 30, methylated alleles were only detected in the adenocarcinoma. In each case, normal leucocyte DNA was used as a negative control for methylation (NL), DNA from normal leucocytes methylated with an excess of Sssl bacterial methyltransferase was used as a positive control for methylation (IVD) and water was used as a negative polymerase chain reaction control $\left(\mathrm{H}_{2} \mathrm{O}\right)$. The Hilo marker is depicted on the right side.

one case the HGPIN lesion overexpressed CRBPI but in the respective PCa this expression was lacking.

\section{Methylation analysis}

Overall, CRBPI promoter hypermethylation was found in 17 cases of PCa and three of 35 HGPIN (fig 2). In one HGPIN lesion, the methylation status could not be assessed owing to insufficient DNA. No significant association was found between loss of CRBPI expression and CRBPI promoter hypermethylation, either in PCa or HGPIN (table 1). The frequency of CRBPl methylation in prostate adenocarcinoma was higher than in HGPIN, and this difference reached

Table 1 Correlation between CRBPI expression and histopathological parameters and methylation status in prostate adenocarcinoma and HGPIN lesions

\begin{tabular}{|c|c|c|c|c|}
\hline & \multicolumn{3}{|c|}{ CRBPI immunoexpression } & \multirow[b]{2}{*}{ p Value } \\
\hline & Increased & Normal & Absent & \\
\hline \multicolumn{5}{|c|}{ Prostate adenocarcinoma $(n=36)$} \\
\hline Gleason score & & & & 0.68 \\
\hline $4-6$ & $10(27.8 \%)$ & $4(11.1 \%)$ & $12(33.3 \%)$ & \\
\hline $7-10$ & $5(13.9 \%)$ & $2(5.6 \%)$ & $3(8.3 \%)$ & \\
\hline Pathological stage & & & & 0.89 \\
\hline pT2a and $\mathrm{pT} 2 \mathrm{~b}$ & $8(22.2 \%)$ & $3(8.3 \%)$ & $9(25.0 \%)$ & \\
\hline pT3a and $\mathrm{pT} 3 \mathrm{~b}$ & $7(19.4 \%)$ & $3(8.3 \%)$ & $6(16.7 \%)$ & \\
\hline Methylation status & & & & 0.54 \\
\hline CRBP1 methylated & $6(16.7 \%)$ & $4(11.1 \%)$ & $7(19.4 \%)$ & \\
\hline CRBPI unmethylated & $9(25.0 \%)$ & $2(5.6 \%)$ & $8(22.2 \%)$ & \\
\hline HGPIN lesions $(n=35)^{*}$ & & & & $0.60 \dagger$ \\
\hline CRBPI methylated & $0(0 \%)$ & $2(5.7 \%)$ & $1(2.9 \%)$ & \\
\hline CRBP1 unmethylated & $9(25.7 \%)$ & $6(17.2 \%)$ & $17(48.5 \%)$ & \\
\hline
\end{tabular}

*In one HGPIN lesion the methylation status could not be assessed; the $p$ value was calculated by grouping together the cases with normal and increased CRBPI expression.

HGPIN, high grade prostatic intraepithelial neoplasia. 


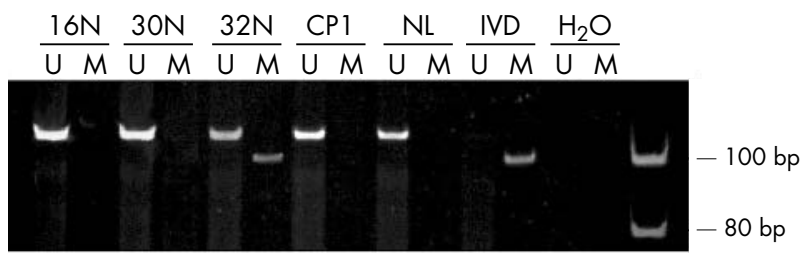

Figure 3 Example of methylation specific polymerase chain reaction for the CRBP1 promoter region in morphologically normal prostate tissue from radical prostatectomy specimens (N) and cystoprostatectomy specimens (CP). Lanes $U$ and $M$ correspond to unmethylated (109 bp) and methylated ( $99 \mathrm{bp}$ ) reactions, respectively. Sample $32 \mathrm{~N}$ shows both unmethylated and methylated alleles, whereas samples $16 \mathrm{~N}, 30 \mathrm{~N}$, and CP1 are completely unmethylated. Normal leucocyte DNA was used as a negative control for methylation (NL), DNA from normal leucocytes methylated with an excess of Sssl bacterial methyltransferase was used as a positive control for methylation (IVD), and water was used as a negative polymerase chain reaction control $\left(\mathrm{H}_{2} \mathrm{O}\right)$. The Hilo marker is depicted on the right side.

significance $(p=0.0004)$. In two HGPIN lesions with CRBPl methylation, the respective PCa was also methylated, whereas in the remaining case of methylated HGPIN the paired adenocarcinoma was unmethylated.

Only one of 36 morphologically normal prostate tissue samples derived from patients simultaneously harbouring prostate cancer displayed CRBPl promoter methylation, and none of the 13 normal prostate tissue samples collected from the cystoprostatectomy specimens showed CRBPl promoter methylation (fig 3).

All BPH lesions analysed were completely unmethylated at the CRBPl promoter.

\section{DISCUSSION}

Altered retinoid metabolism is thought to play an important, yet not fully understood, role in the development of several human tumours. ${ }^{2-5}$ Moreover, the effects of retinoids mediated by nuclear receptors seem to depend upon the function of CRBPs. ${ }^{78}$ Owing to the lack of data concerning the relevance of CRBPl in prostate tumorigenesis, we assessed CRBPl expression and the methylation pattern of this gene in PCa and precursor (HGPIN) lesions. We show here that both altered CRBPl expression and promoter hypermethylation are common events in prostate cancer.

Our immunohistochemical results show that CRBPl expression is frequently lost in PCa and HGPIN $(41.7 \%$ and $50 \%$, respectively), being a more frequent event than reported for breast invasive and in situ carcinomas or ovarian cancer. ${ }^{11}{ }^{12}$ Cvetković and co-workers showed that the results of quantitative PCR to measure CRBPI expression were in complete agreement with the immunohistochemical analysis performed in ovarian carcinoma. ${ }^{12}$ Hence, the approach used in our study to assess CRBPl expression is reliable and it also allows for immunolocalisation analysis, precluding the need for laser capture microdissection of prostate lesions. The high proportion of loss of CRBPI expression both in PCa and HGPIN suggests that this alteration may be an important event in prostate carcinogenesis. In breast cancer cell lines, it has been hypothesised that CRBPl would be involved in the promotion of apoptosis through an increase in all-trans retinoic acid synthesis. ${ }^{11}$ Because suppression of apoptosis seems to play a key role in prostate carcinogenesis, ${ }^{14}$ the observed loss of CRBPl in prostate neoplastic cells could disrupt a retinoic acid mediated apoptosis pathway.

Interestingly, 15 of $36 \mathrm{PCa}$ cases and nine of 36 cases of HGPIN showed CRBPl overexpression, compared with normal glands. Such a finding has not been described in other epithelial neoplasms, but was reported in leiomyosarcomas, particularly in the epithelioid variant. ${ }^{21}$ A significant association was then established between CRBPl overexpression and tumour differentiation, ${ }^{21}$ but such an association was not found among our patients with prostate cancer, taking the Gleason score as a measure of neoplastic differentiation (data not shown). At first glance, CRBPI overexpression may seem a disadvantageous acquisition by prostate cancer cells, but this change could represent a side effect of the altered expression of other genes in a subset of prostate tumours, rather than a primary event in prostate carcinogenesis. A probable candidate would be the gene encoding transforming growth factor $\beta 1$, because this gene is frequently upregulated in prostate cancer, ${ }^{22}$ and it has been reported to induce CRBPI overexpression. ${ }^{23}$ Alternatively, an increase in CRBPl cytoplasmic values could result from an abnormal (that is, less effective) pathway of protein degradation, as previously reported for other proteins. ${ }^{24}$

"Because suppression of apoptosis seems to play a key role in prostate carcinogenesis, the observed loss of CRBP1 in prostate neoplastic cells could disrupt a retinoic acid mediated apoptosis pathway"

In most (28 of 36) cases, the pattern of CRBPl expression in paired PCa and HGPIN lesions was concordant, supporting the purported adenocarcinoma precursor role of HGPIN. ${ }^{25}$ However, in seven cases, CRBPl was overexpressed in the adenocarcinoma whereas decreased or normal values were seen in the paired HGPIN. This observation, in addition to the remaining discordant case in which the HGPIN lesion displayed CRBPl overexpression and the adenocarcinoma showed loss of expression, could be explained by the well known genetic heterogeneity that characterises prostate tumours. ${ }^{26}$

Aberrant methylation was a frequent finding in our series of prostate adenocarcinomas $(42.2 \%)$. This frequency is similar to that reported for gastric cancer by Esteller et al, making prostate adenocarcinoma one of the cancers where this gene is most frequently methylated. ${ }^{13}$ However, we did not find a correlation between methylation and the lack of CRBPI expression, whereas in that study a close relation between CRBPl methylation and lack of expression was shown in several tumour cell lines and preneoplastic lesions. ${ }^{13}$ Thus, additional mechanisms may be responsible for CRBPl silencing in prostate carcinogenesis, although no mutations or loss of heterozygosity $(\mathrm{LOH})$ have yet been described for this gene. Indeed, frequent $\mathrm{LOH}$ has been reported at 3p24-26 and 3p12-22 in prostate adenocarcinoma, ${ }^{27}$ but not at 3 q23, the chromosomal band that CRBPl has been mapped to. ${ }^{28}$ An alternative explanation would be the existence of a critical level of methylation for the silencing of CRBPl, as we have suggested previously for GSTP1. ${ }^{29}{ }^{30}$ Strikingly, in ovarian cancer, the prevalence of the

\section{Take home messages}

- Altered expression and promoter hypermethylation of the CRBP1 gene, which encodes cellular retinol binding protein 1, occur frequently in prostate carcinoma, although CRBPI hypermethylation is not an early event in tumorigenesis

- Both adenocarcinoma and high grade prostatic intraepithelial neoplasia show frequent CRBPI overexpression

- The molecular mechanisms underlying altered CRBP1 expression in prostate cancer deserve further study 
lack of CRBPl expression (35\%) reported by Cvetković and colleagues $^{12}$ contrasts with the notable absence of CRBPI methylation seen by Esteller et al. ${ }^{13}$ Moreover, several cases of prostate adenocarcinoma with both CRBPI promoter methylation and protein expression were found in our series. A possible explanation for this finding would be monoallelic expression of CRBP1, in which case only one allele would be methylated. Interestingly, monoallelic expression of RAR $\beta 2$ in breast cancer has also been suggested for cases in which $\mathrm{LOH}$ was found at this gene locus. ${ }^{31}$ The relevance of other genetic events for the high frequency of loss of CRBPI expression seen by immunohistochemical analysis clearly warrants further study.

CRBPI methylated alleles were found in only one sample of normal prostate tissue derived from patients with prostate cancer, and the respective tumour showed the same methylation status. Aberrant promoter methylation has been reported in normal tissues from several sites and was eventually related to aging. ${ }^{32}$ However, the occurrence of a single case of CRBPl methylation in morphologically normal tissue from a patient simultaneously harbouring a prostate cancer with the same alteration should raise the possibility of contamination, although precautions were taken to prevent this event. Furthermore, the possibility that this epigenetic change might occur in morphologically normal cells as a potential premalignant characteristic cannot be ruled out because CRBPI methylation was not seen in normal prostate tissue derived from patients without prostate cancer, or in $\mathrm{BPH}$ tissue samples.

Our study indicates that CRBPl methylation in HGPIN is a considerably less frequent event than in adenocarcinoma $(8.6 \% \vee 47.2 \%)$. Hence, this epigenetic alteration does not seem to occur frequently in the early steps of prostate carcinogenesis. It is worthwhile noting that both colorectal and gastric adenomas frequently display methylation of the CRBPI promoter region, and this frequency parallels that seen in their invasive counterparts. ${ }^{13}$ These findings suggest that the acquisition of CRBPl aberrant methylation may occur at different steps of the tumorigenic process, depending upon the biological characteristics of each neoplasm.

\section{ACKNOWLEDGEMENTS}

CJ is supported by a grant from the Fundação para a Ciência e Tecnologia, Portugal (SFRH/BPD 8031/2002). Funding for this study was provided by the Portuguese Ministry of Health (Comissão para o Fomento da Investigação em Cuidados de Saúde, Project no. 220/ 2001). The support of Liga Portuguesa Contra o Cancro - Núcleo Regional do Norte is gratefully acknowledged.

\section{Authors' affiliations}

C Jerónimo, M R Teixeira, Department of Genetics, Portuguese Oncology Institute-Porto, Rua Dr António Bernardino de Almeida, 4200072 Porto, Portugal

R Henrique, I Pais, C Lopes, Department of Pathology, Portuguese Oncology Institute-Porto

J Oliveira, F Lobo, Department of Urology, Portuguese Oncology Institute-Porto

R Henrique, M R Teixeira, C Lopes, Department of Pathology and Molecular Immunology, Institute of Biomedical Sciences Abel Salazar, University of Porto, Largo Prof. Abel Salazar 2, 4099-003 Porto, Portugal

The first two authors contributed equally to this study and should be regarded as joint first authors

\section{REFERENCES}

1 Gudas L. Retinoids and vertebrate development. J Biol Chem 1994;269: 15399-402.
2 Pastorino U, Infante M, Maioli $M$, et al. Adjuvant treatment of stage I lung cancer with high-dose vitamin A. J Clin Oncol 1993;11:1216-22.

3 Ki Hong W, Lippman SM, Hittelman WN, et al. Retinoid chemoprevention of aerodigestive cancer: from basic research to the clinic. Clin Cancer Res 1995; 1:677-86.

4 Lippman SM, Lotan R. Advances in the development of retinoids as chemopreventive agents. J Nutr 2000;130:479S-82S

5 Chambon $\mathrm{P}$. A decade of molecular biology of retinoic acid receptors. FASEB J 1996; 10:940-54

6 Anzano MA, Peer CW, Smith JM, et al. Chemoprevention of mammary carcinogenesis in the rat: combined use of raloxifene and 9-cis-retinoic acid. J Natl Cancer Inst 1996:88:123-5.

7 Folli C, Calderone V, Ottonello S, et al. Identification, retinoid binding, and $\mathrm{X}$-ray analysis of a human retinol-binding protein. Proc Natl Acad Sci U S A $2001 ; 98: 3710-15$.

8 Vogel S, Mendelsohn CL, Mertz JR, et al. Characterization of a new member of the fatty acid-binding protein family that binds all-trans-retinol. J Biol Chem $2001 ; 276: 1353-60$

9 Kuppumbatti YS, Rexer B, Nakajo S, et al. CRBP suppresses breast cancer cell survival and anchorage independent growth. Oncogene 2001;20:7413-19.

10 Ghyselinck NB, Bavik C, Sapin V, et al. Cellular retinol-binding protein I is essential for vitamin A homeostasis. EMBO J 1999;18:4903-14.

11 Kuppumbatti YS, Bleiweiss IJ, Mandeli JP, et al. Cellular retinol-binding protein expression and breast cancer. J Natl Cancer Inst 2000:92:475-80.

12 Cretković D, Williams SJ, Hamilton TC. Loss of cellular retinol-binding protein 1 gene expression in microdissected human ovarian cancer. Clin Cancer Res 2003;9:1013-20.

13 Esteller M, Guo M, Moreno V, et al. Hypermethylation-associated inactivation of the cellular retinol-binding protein 1 gene in human cancer. Cancer Res 2002;62:5902-5

14 Zhang XK. Vitamin A and apoptosis in prostate cancer. Endocr Relat Cancer 2002:9:87-102.

15 Gleason DF, Mellinger GT, Veterans Administration Cooperative Urological Research group. Prediction of prognosis for prostatic adenocarcinoma by combined histologic grading and clinical staging. J Urol 1974;111:58-64

16 Hermanek P, Hutter RVP, Sobin LH, et al. Prostate. In: Hermanek P, Hutter RVP, Sobin LH, et al. Illustrated guide to the TNM/pTNM classification of malignant tumors, 4th ed. Heidelberg: Springer-Verlag, 1997:272-80.

17 Neuville P, Geinoz A, Benzonana G, et al. Cellular retinol-binding protein-1 is expressed by distinct subsets of rat arterial smooth muscle cells in vitro and in vivo. Am J Pathol 1997; 150:509-21.

18 Ahrendt SA, Chow JT, Xu LH, et al. Molecular detection of tumor cells in bronchoalveolar lavage fluid from patients with early stage lung cancer. J Natl Cancer Inst 1999:91:332-9.

19 Olek A, Oswald J, Walter JA. A modified and improved method of bisulfite based cytosine methylation analysis. Nucleic Acids Res 1996;24:5064-6.

20 Herman JG, Graff JR, Myohanen S, et al. Methylation-specific PCR: a novel PCR assay for methylation status of $\mathrm{CpG}$ islands. Proc Natl Acad Sci U S A 1996;93:9821-6.

21 Orlandi A, Francesconi A, Clement S, et al. High levels of cellular retinol binding protein-1 expression in leiomyosarcoma: possible implications for diagnostic evaluation. Virchows Arch 2002;441:31-40.

22 Steiner MS. Transforming growth factor-beta and prostate cancer. World J Urol 1995;13:329-36.

23 Xu G, Bochaton-Piallat M-L, Andreutti D, et al. Regulation of $\alpha$-smooth muscle actin and CRBP-1 expression by retinoic acid and TGF- $\beta$ in cultured fibroblasts. J Cell Physiol 2001;187:315-25.

24 Hershko A, Ciechanover A, Varshavsky A. Basic medical research award. The ubiquitin system. Nat Med 2000;6:1073-81

25 Haggman MJ, Macoska JA, Wojno KJ, et al. The relationship between prostatic intraepithelial neoplasia and prostate cancer: critical issues. J Urol 1997; 158:233-7

26 Qian J, Bostwick DG, Takahashi S, et al. Chromosomal anomalies in prostatic intraepithelial neoplasia and carcinoma detected by fluorescence in situ hybridization. Cancer Res 1995;55:5408-14.

27 Dahiya R, McCarville J, Hu W, et al. Chromosome 3p24-26 and 3p22-12 loss in human prostatic adenocarcinoma. Int J Cancer 1997:71:20-5.

28 De Baere E, Speleman F, Van Roy N, et al. Assignment of the cellular retinolbinding protein 1 gene (RBP1) and of the coatomer beta subunit gene (COPB2) to human chromosome band $3 q 23$ by in situ hybridization. Cytogenet Cell Genet 1998:82:226-7.

29 Jerónimo C, Usadel H, Henrique R, et al. Quantitation of GSTP1 hypermethylation distinguishes between non-neoplastic prostatic tissue and organ confined prostate adenocarcinoma. J Natl Cancer Inst 2001;93:1747-52

30 Jerónimo C, Varzim G, Henrique R, et al. $1105 \mathrm{~V}$ polymorphism and promoter methylation of GSTP1 gene in prostate adenocarcinoma. Cancer Epidemiol Biomark Prev 2002;11:445-50.

31 Yang Q, Mori I, Shan L, et al. Biallelic inactivation of retinoic acid receptor beta2 gene by epigenetic change in breast cancer. Am J Pathol 2001;158:299-303.

32 Waki T, Tamura G, Sato M, et al. Age-related methylation of tumor suppressor and tumor-related genes: an analysis of autopsy samples. Oncogene 2003;22:4128-33. 